\title{
Do Cairo a Nairóbi: 25 anos da agenda de população e desenvolvimento no Brasil
}

\author{
Richarlls Martins*
}

Este artigo objetiva analisar os marcadores em âmbitos nacional, regional e global referentes aos 25 anos da Conferência Internacional de População e Desenvolvimento (CIPD), celebrados em 2019. A partir da identificação dos temas, atores, instituições e estratégias que constituem este processo, com especial ênfase analítica nos movimentos políticos da sociedade civil brasileira que atuam no interior do escopo programático desta agenda, o texto problematiza as possibilidades, avanços, lacunas e desafios da implementação da CIPD nacionalmente, no atual contexto político e social brasileiro.

O tema populacional está presente no escopo de atenção das Nações Unidas desde os primórdios de sua fundação, em 1945, refletindo o campo de tensão geopolítico e as preocupações governamentais que se inscrevem em perspectiva histórica, sendo, já no ano seguinte de sua criação, constituída a Comissão de População da ONU (BERQUÓ, 1999, 2014).

Um eixo constitutivo dos estudos que analisam este processo ancora-se na afirmação de que crescimento populacional e a relação fecundidade/crescimento econômico são os elementos centrais de estruturação dos acordos entre os países no interior desta agenda. Em âmbito nacional, este foi um dos eixos centrais de modulação das políticas pré-Conferência Internacional de População e Desenvolvimento CIPD 1994, que ancoraram-se ora numa perspectiva controlista, ora em ações pró-natalistas.

\footnotetext{
* Universidade Federal do Rio de Janeiro (UFRJ), Fundação Oswaldo Cruz (Fiocruz), Rio de Janeiro-RJ, Brasil (richarlls@ hotmail.com; https://orcid.org/0000-0003-3443-1610).
} 
As quarto Conferências de População que antecederam a CIPD 1994 (Roma 1954, Belgrado 1965, Bucareste 1974 e México 1984) se propuseram a responder a esta questão central alocada no binômio crescimento populacional e desenvolvimento econômico, a partir do entendimento da população como "entrave" ao desenvolvimento (CAMARANO, 2013; ALVES, 2014), reeditando sob o signo de Malthus, à luz do século XX, o temário da população como problema, que se expressaria na impossibilidade de países com alto crescimento populacional obterem desenvolvimento econômico.

A CIPD 1994 promoveu uma ruptura e deslocamento conceitual no campo das políticas de população em âmbito global, ao deslocar a concepção essencialmente numérica, até então vigente, com base no crescimento e projeção populacional, para uma orientação que considera a população detentora de direitos (BERQUÓ, 1999, 2014; ARILHA; LAGO, 2014; ABEP/UNFPA, 2004, 2009; CAMARANO, 2013). Como amplamente se aponta na produção bibliográfica sobre estes postulados, a agenda do Cairo produziu um novo paradigma na compreensão e respostas sobre os estudos de população, reorganizando na esfera multilateral as definições sobre as políticas populacionais (BERQUÓ, 1999).

É possível afirmar que o Brasil antecipou em uma década a indução de elementos do Programa de Ação da CIPD. A forte internacionalização de ativistas sociais do movimento feminista brasileiro, ainda no início dos anos 1980, e a construção de articulações internas e globais desta sociedade civil em diálogo com o governo brasileiro no processo de reabertura democrática no marco das políticas para mulheres e das políticas de saúde são chaves de leitura para entender esta constituição.

Ao analisar como fonte de dados os documentos oficiais de credenciamento para composição das delegações da CIPD e dos espaços intergovernamentais correlatos à agenda de população e desenvolvimento nestes 25 anos de seguimento, identifica-se que $75 \%$ da sociedade civil brasileira que monitora esta agenda internacionalmente é composta por mulheres que atuam diretamente no campo das políticas de saúde, nos eixos da sexualidade, reprodução e gênero (MARTINS, 2017).

Este dado ajuda a entender a forte presença deste eixo temático na estruturação do advocacy nacional na CIPD e seus desdobramentos, além de, numa outra linha de análise, auxiliar na reflexão sobre as dificuldades de visibilizar outros tópicos da agenda, que não se inscrevem diretamente nesta tríade.

A preparação da sociedade civil para a Conferência do Cairo em 1994 inscreve-se na experiência inédita de diálogo entre movimentos sociais e governo, no marco da política externa. A CIPD 1994 foi o primeiro fórum multilateral no qual o Brasil credenciou representantes da sociedade civil não acadêmica em sua delegação, inaugurando uma nova forma de participação social na política externa (MARTINS, 2017).

É possível identificar, nesse contexto, uma forte abertura para o diálogo da chancelaria nacional e mudança de postura do Itamaraty, que passou a realizar seminários preparatórios para a CIPD, com participação da sociedade civil e representantes da academia, objetivando colher contribuições para o documento oficial do Brasil. 
No curso dos temários atualizados do Programa de Ação da CIPD, a regionalização da agenda, processo iniciado em 2012 com a mudança do status do Comitê de População da Comissão Econômica para a América Latina (Cepal) para Conferência Regional de População e Desenvolvimento da América Latina e Caribe (CRPDALC), é um elemento central para entender os caminhos contemporâneos de indução da agenda no Brasil.

Nesse sentido, a aprovação do Consenso de Montevideo sobre População e Desenvolvimento da América Latina e Caribe, ${ }^{1}$ em 2013, marcou, de um lado, o maior avanço de linguagem em âmbito global, ampliando a indissociabilidade dos direitos humanos nos temas de população, mas, de outro, restringiu a um continente a escala da universalidade dos direitos humanos.

A última reunião da mesa diretora da CRPDALC, da qual o Brasil é um dos vice-presidentes, realizada em outubro de 2019 na Cepal em Santiago, expressa a complexidade da conjuntura. 0 principal ponto de questionamento do Acordo ${ }^{2}$ aprovado foi a referência sobre migração internacional, alvo de destaques e resistência na negociação pela representação diplomática do Brasil, sob o argumento de que "migração internacional não deveria ser tratada no Acordo por não ser um tema do mandato da CRPDALC".

Se, por um lado, há no Consenso de Montevideo uma formulação progressista sobre o tema, na qual o Brasil regionalmente se vincula, por outro, a primeira ação da política externa de relevância do atual governo em janeiro de 2019 foi solicitar à ONU a desvinculação do país do Pacto Global de Migração, aprovado em dezembro em 2018 e do qual o Brasil foi, por meio do Departamento de Direitos Humanos e Temas Socias do Ministério das Relações Exteriores, um dos líderes na negociação, à luz do marco legal nacional avançado neste temário aprovado, com base na Lei de Imigração promulgada em 2017.

0 governo brasileiro foi um dos poucos a não apresentar informe de país sobre o status de implementação da agenda regional de população e desenvolvimento no fórum da CRPDALC, em 2019, marcado pelos 25 anos da CIPD. 0 último documento público do Brasil de monitoramento da agenda, ${ }^{3}$ produzido após pressão da sociedade civil, foi apresentado na III CRPDALC, realizada em agosto de 2018 em Lima.

Na discussão sobre a análise da implementação da agenda de população e desenvolvimento no Brasil nestes 25 anos, em âmbito institucional, é importante observar o papel da Comissão Nacional de População e Desenvolvimento (CNPD). A Comissão, instituída em 1995, apresenta como missão contribuir para a formulação de políticas relativas aos temas de população e desenvolvimento.

Este fórum é o principal espaço de monitoramento da agenda de população e desenvolvimento no Brasil, mas com limitado papel definidor de políticas. Desde o início do atual

\footnotetext{
1Disponível em: 〈https://www.cepal.org/pt-br/publicaciones/21884-consenso-montevideu-populacao-desenvolvimento〉.

${ }^{2}$ Acordo da mesa diretora da Conferência Regional de População e Desenvolvimento da América Latina e Caribe 2019. Disponivel em: 〈https://crpd.cepal.org/4m/sites/crpd4m/files/19-00935_mdp.4_acuerdos.pdf〉.

${ }^{3}$ Informe do Brasil na III Conferência Regional de População e Desenvolvimento da América Latina e Caribe 2018. Disponível em: 〈https://crpd.cepal.org/3/sites/crpd3/files/relatorio_brasil.pdf〉.
} 
governo em 2019, a CNPD encontra-se extinta e não há nenhuma instância governamental responsável pela condução dos postulados da CIPD no Brasil.

A publicação pela Assembleia Geral das Nações Unidas da Resolução n. 65/234, em 2010, que amplia a extensão da CIPD, define pela não realização de uma Conferência de Revisão. Esta decisão constitui um marcador fundamental analítico da configuração geopolítica da agenda global de população, a partir da posição de que o contexto internacional vigente não se configura favorável para a abertura de negociação em âmbito multilateral neste campo, em função do aumento dos países conservadores.

Entre 2012 e 2019, acompanhei presencialmente todas as sessões da Comissão de População e Desenvolvimento (CPD) da ONU e é possível verificar, pós-2014, uma inflexão no diálogo entre países sobre os temas populacionais. Os fóruns intergovernamentais posteriores aos 20 anos da CIPD, no marco das CPD, entre 2015 e 2019, conseguiram aprovar apenas uma resolução, visibilizando a enorme dificuldade, até então não presente nesta proporção pós-CIPD, de diálogo sobre uma agenda de população, em âmbito multilateral.

$\mathrm{Na}$ escala nacional, vivencia-se a inscrição deste processo geopolítico de recrudescimento conservador. Após 25 anos da CIPD, opera-se, desde o início de 2019 no Brasil, uma ruptura paradigmática no escopo de indução de políticas públicas em eixos centrais de disputa no interior desta agenda e emerge uma mudança histórica na tradição da política externa brasileira, de não alinhamento à defesa integral dos direitos humanos, perspectiva inédita desde a redemocratização.

Este quadro afetou diretamente uma análise integral por parte dos múltiplos atores relacionados com o aniversário da CIPD em âmbito nacional. As ações em torno da avaliação brasileira sobre a implementação do Cairo+25 estão coordenadas majoritariamente pela sociedade civil e não foi realizada nenhuma avaliação, informe documental e/ou evento sobre os 25 anos da CIPD pelo governo brasileiro.

Em agosto de 2018, no marco do "Il Diálogos Brasileiros de População e Desenvolvimento - Marielle Franco, presente”, realizado pela Rede Brasileira de População e Desenvolvimento (REBRAPD) no Rio de Janeiro, foi aprovada a constituição da Plataforma Cairo+25 Brasil, ${ }^{4}$ que entre maio e outubro de 2019 realizou 14 eventos (um em cada região do país; consultas específicas sobre LGBTQI, imigração, HIV/Aids, indígenas; três consultas com comunidade científica e duas ações internacionais) com objetivo de ampliar a participação da sociedade civil e da comunidade científica nos debates sobre os 25 anos da CIPD.

A REBRAPD, Fiocruz e UFRJ, em novembro de 2019, realizaram o "Seminário Nacional Cairo+25: desafios para agenda de população e desenvolvimento no Brasil", 5 maior evento na América Latina e Caribe sobre os 25 anos da CIPD, com lançamento do Relatório Luz da Sociedade Civil sobre os 25 anos da CIPD, fruto dos encontros desta Plataforma.

\footnotetext{
4 Documento aprovação da Plataforma Cairo+ 25 Brasil disponível em: 〈https://www.rebrapd.com.br/2018/08/apoiointernacional-cairo-25-brasil.html.

${ }^{5}$ Programação do Seminário disponível em: 〈https://portal.fiocruz.br/sites/portal.fiocruz.br/files/documentos/ programa_seminario_cairo25.pdf〉.
} 
A institucionalização formal do processo Cairo+25 em âmbito global apresentou limitações quanto ao planejamento e engajamento dos atores neste processo. As primeiras ações públicas de difusão começaram a ser desenhadas com informes públicos limitados e abertos somente em janeiro de 2019 pelo UNFPA global.

Nesta condução, é importante ampliar o escopo de análise sobre o papel do UNFPA neste terreno, o poder definidor desta agência sobre os postulados a serem priorizados e as limitações do mandato que este órgão possui no complexo diálogo com governos refratários à integralidade do Programa de Ação da CIPD, como o brasileiro na atualidade.

Em final de fevereiro de 2019, o UNFPA América Latina e Caribe (Lacro) organizou uma primeira reunião com organizações da sociedade civil no Panamá para apresentar as linhas iniciais em torno dos 25 anos da CIPD global e regionalmente. Nesta atividade, que contou com a participação de aproximadamente 30 representantes, os temas priorizados foram juventude, direitos e saúde sexual e reprodutiva e igualdade de gênero, sendo apresentada a proposta da Cúpula de Nairóbi CIPD25, organizada pelo UNFPA e governos do Quênia e da Dinamarca.

Contudo, é importante elencar as críticas direcionadas ao UNFPA quanto à realização de uma ação global com poucos meses de articulação e limitações financeiras. Aprovou-se a construção de uma rota América Latina e Caribe-Nairóbi, na qual a sociedade civil trabalhou em diálogo com o UNFPA Lacro na produção de agenda, documento político e participação para a realização de uma reunião regional.

Entre março e abril, ocorreram três diálogos presenciais entre representantes deste grupo da sociedade civil com o UNFPA Lacro, no marco de eventos já constituídos, no México, Nova York e Santiago. Nos meses seguintes, as atividades centraram-se em duas comissões de trabalho sobre programa/participação e conteúdo/documento. Neste percurso, o UNFPA global nomeou o comitê central da Cúpula de Nairóbi, com responsabilidade de organizar a Conferência, contando com a participação de três representantes da América Latina.

A REBRAPD foi a única organização da sociedade civil do Brasil a participar presencialmente de todo este processo de reuniões e organização dos 25 anos da CIPD, articulando regional e globalmente os encaminhamentos no marco da Plataforma Cairo+25 Brasil.

A reunião regional preparatória da América Latina e Caribe para a Cúpula de Nairóbi, realizada em final de setembro de 2019 em Puebla, no México, contou com aproximadamente 200 participantes convidados pelo UNFPA, entre representantes governamentais, do setor privado, representantes do sistema ONU e majoritariamente sociedade civil. Esta atividade foi precedida por um Acampamento de Juventude e um encontro específico dos países caribenhos.

A delegação brasileira neste fórum foi composta por: Blenda Leite, assessora do Conselho Nacional de Secretários Municipais de Saúde do Brasil (Conasems); Charles Tocantis, vice-presidente do Conasems; Júnia Quiroga, representante interina do UNFPA no Brasil; Matheus Valois, coordenador de comunicação dos Escoteiros no Brasil; Priscila 
Carvalho, coordenadora da área técnica de saúde dos adolescentes e jovens do Ministério da Saúde; e Richarlls Martins, coordenador da REBRAPD.

A atividade apresentou três eixos de discussão: diversidade demográfica, igualdade de gênero e saúde sexual e reprodutiva. 0 documento final aprovado denominado Un asunto pendiente: la defensa de los derechos y la libertad de decidir de todas las personas - Los compromisos de Puebla ${ }^{6}$ é um convite para que governos, parlamentares, movimentos sociais, meios de comunicação, setor privado, academia e organismos internacionais assumam 25 compromissos, alinhados ao Consenso de Montevideo de População e Desenvolvimento da América Latina e Caribe, no marco dos 25 anos da CIPD. A REBRAPD apresentou um documento de compromiso com três pontos correlatos ao seguimento no Brasil do monitoramento pela sociedade civil nos próximos cinco anos da agenda.

A Cúpula de Nairóbi, ${ }^{7}$ que marcará em âmbito global os 25 anos da CIPD, definiu cinco temas e cinco aceledores considerados centrais para suprir as lacunas e avançar na implementação da agenda de população e desenvolvimento. É importante problematizar, em uma avaliação atenta após o documento final deste processo, como estes temas priorizados serão capazes de articular a integralidade do Programa de Ação da CIPD e não ampliar a marginalização de pautas importantes, como a questão ambiental e climática, no marco da agenda.

Os cinco temas específicos são: acesso universal à saúde e direitos sexuais e reprodutivos como parte da cobertura universal de saúde; financiamento necessário para concluir o Programa de Ação da CIPD e sustentar os ganhos obtidos; aproveitar a diversidade demográfica para impulsionar o crescimento econômico e alcançar o desenvolvimento sustentável; eliminar a violência baseada em gênero e práticas nocivas contra meninas e mulheres; e defender o direito à saúde sexual e reprodutiva em contextos humanitários e frágeis.

Na mesma perspectiva, este processo elencou cinco aceleradores, considerados questões transversais essenciais para ampliar as ações dentro de cada tema, enfatizando a urgência de ação, políticas e programas para cumprir a CIPD, a partir de cinco elementos: empoderamento das mulheres e igualdade de gênero; liderança e engajamento juvenil; liderança política e comunitária; inovação e dados; e parcerias estratégicas e colaboração Sul-Sul.

Os eixos políticos constitutivos da ação global de celebração dos 25 anos da CIPD estão centrados no enfrentamento de três zeros: zero necessidade não atendida de planejamento familiar; zero mortes maternas evitáveis; e zero violência de gênero e práticas prejudiciais contra mulheres, meninas e jovens.

A representação brasileira, convidada pelo UNFPA a participar deste fórum de alto nível com múltiplos atores que atuam na agenda da CIPD, não é marcada por uma delegação oficial, dada a natureza deste processo que não se caracteriza como mecanismo de negociação intergovernamental.

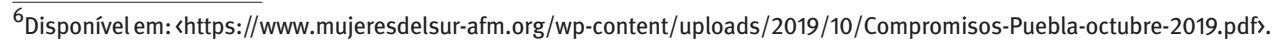

${ }^{7}$ Ver: «https://www.nairobisummiticpd.org/〉.
} 
Observando os atores nacionais ${ }^{8}$ que compõem a Cúpula de Nairóbi CIPD 25, é possível identificar a centralidade de representações ligadas ao campo da saúde, que pode ser explicada em âmbito governamental pela reunião da Coalização Global de Prevenção ao HIV, que ocorrerá previamente à Cúpula, pela definição de prioridade de trabalho em 2019 do UNFPA com o Ministério da Saúde no Brasil e a assinatura do Memorando de Entendimento do UNFPA global com a Fiocruz, em julho deste ano.

Destaca-se, ao comparar a participação da sociedade civil brasileira atual, que incidirá em Nairóbi, em relação à CIPD de 1994, a ampliação da participação do tema da juventude e ativistas jovens neste processo, bem como diminuição de redes ligadas diretamente ao movimento feminista, que foram protagonismas da preparação do movimento social que atuou diretamente na CIPD 25 anos atrás.

Um ponto de inflexão analítica relevante, que demanda avaliação aprofundada após a Cúpula de Nairóbi, é ampliar o escopo reflexivo sobre o comportamento das representações do governo brasileiro, com especial atenção dos órgãos do MRE e MMFDH que participaram do referido fórum. A confirmação dos membros destes dois ministérios ocorreu dez dias antes do início da Cúpula e foi recebida com surpresa pelos atores institucionais que monitoram o seguimento da agenda de população e desenvolvimento, em função da baixa intensidade de participação governamental no processo dos 25 anos da CIPD 1994.

O Brasil apresenta-se em Nairóbi, na celebração dos 25 anos CIPD, com 75,5\% de negros vítimas de homicídios (Atlas da Violência, Ipea, 2019) e 812 mil brasileiros privados de liberdade, sendo 54\% sem nenhuma condenação (Conselho Nacional de Justiça, 2019). Somente no Rio de Janeiro, nos primeros oito meses de 2019, foram registradas 1.250 mortes por operações da Polícia Militar (Instituto de Segurança Pública, 2019). Em âmbito nacional, de cada dez jovens negros de 19 a 24 anos, 4,4 não terminaram o ensino médio (PNAD/IBGE, 2019) e a taxa de suicídio entre os jovens negros é $45 \%$ mais alta do que entre jovens brancos (Relatório mortes por suicídio entre adolescentes e jovens negros, Ministério da Saúde, 2019).

\footnotetext{
${ }^{8}$ Representantes do Brasil na Cúpula de Nairóbi CIPD 25: Angela Gandra, secretária nacional da família do Ministério da Mulher, da Família e dos Direitos Humanos (MMFDH); Astrid Bant, representante do UNFPA no Brasil; Beatriz Galli, assessora de advocay para América Latina e Caribe do Ipas; Bernardo Mota, membro da Rede TransDF; Cláudia Giovannetti, assessora para assuntos de refugiados do MMFDH; Clarissa Barros, técnica do Ministério da Saúde (MS); Cleiton Euzébio, diretor interino do Unaids no Brasil; Cristiani Vieira Machado, vice-presidente de educação, comunicação e informação da Fundação Oswaldo Cruz (Fiocruz); Elizabeth Silva, coordenadora da Rede CCAP Manguinhos (Fiocruz); Fernando Coimbra, embaixador do Brasil em Nairóbi; Georgia Mota, coordenadora dos informes nacionais do MMFDH; Gustavo Barbosa, primeiro-secretário da Embaixada do Brasil em Nairóbi; Jackeline Romio, secretária da Associação Latinoamericana de População; Julieta Palmeira, secretária de políticas para mulheres da Bahia; Júnia Quiroga, representante auxiliar do UNFPA no Brasil; Lorenza Longhi, técnica do MS; Kelly Aguiar, especialista MSD Farmacêutica; Luiz Augusto Galvão, assessor da Fiocruz; Margareth Arilha, coordenadora da Comissão de Cidadania e Reprodução; Matheus Carvalho, primeiro-secretário da Divisão de Cidadania do Departamento dos Direitos Humanos e Cidadania do Ministério das Relações Exteriores (MRE); Matheus Valois, coordenador de comunicação dos Escoteiros do Brasil; Maximiliano Marques, diretor do Departamento de Ações Programáticas Estratégicas do MS; Nísia Trindade, presidente da Fiocruz; Olivia Santana, deputada estadual da Bahia; Patrick Luna, segundo secretário do MRE; Rayanne França, coordenadora da Rede Nacional de Jovens Indígenas; e Richarlls Martins, coordenador da REBRAPD.
} 
Os temas de população, escopo do Programa de Ação da CIPD, são elementos centrais de ação da incidência no marco das políticas de restauração conservadora do atual governo brasileiro. Um dos focos principais de estruturação das políticas públicas desde janeiro de 2019 centra-se na promoção de medidas com base no enfrentamento à ideologia de gênero, no marco da instalação de políticas antigênero e de promoção de uma agenda de direitos em dissonância com os acordos internacionais aprovados desde a Declaração Universal dos Direitos Humanos, especialmente a CIPD.

No contexto atual, é necessário recordar que gênero, linguagem consagrada e defendida internacionalmente, foi descrito pela primeira vez em um documento intergovernamental na CIPD. Apresenta-se em curso no Brasil uma indução de afirmar a igualdade entre homens e mulheres, a partir de uma perspectiva biológica, na qual a igualdade de gênero passa a ser elemento narrativo de disputa.

Há uma marcação pautada num único modelo de família, em total dissonância ao disposto na formulação de pluralidade familiar presente na CIPD de 25 anos atrás. Opera-se o mesmo na promoção, em âmbito nacional, das políticas no campo dos direitos sexuais, educação integral em sexualidade, direito ao aborto, pessoas com deficiência, população negra e povos indígenas, avanços de linguagem obtidos com o Consenso de Montevideo sobre População e Desenvolvimento da América Latina e Caribe.

Nesse sentido, apontam-se, no curso dos 25 anos da CIPD no Brasil, postulados que emergem com destaque e afetam diretamente a indução para a implementação de uma agenda integral de população e desenvolvimento. É necessário ampliar o escopo reflexivo sobre os discursos com base na ideologia de gênero e políticas antigênero, o retorno à naturalização das categorias homem e mulher, o recrudescimento de um discurso nacionalista, a divissibilidade dos direitos humanos e a disputa de sentido da linguagem junto aos temas dos direitos sexuais e reprodutivos.

Os 25 anos da CIPD são mais do que uma oportunidade normativa e formal de revisão dos avanços, lacunas e desafios dos temas de população. A maior potência deste processo é a possibilidade de articular o tecido social na reconstrução dos caminhos desta agenda, reafirmar a mudança de paradigma advinda da CIPD e ampliar a pactuação do consenso civilizatório produzido no Cairo em 1994, à luz do tempo presente e das demandas indivisíveis de uma pauta geopolítica global sustentável.

Nesse terreno, ampliar o escopo analítico do papel do Brasil nesta nova engrenagem de governança multipolar pós-2020, no marco das políticas populacionais, é missão central. A incerteza do cenário nacional e as limitações de âmbito interno direcionam com maior vocalidade o desafio de defender a integralidade da CIPD na produção de linhas de cooperação.

Ao analisar este percurso Cairo-Nairóbi, é urgente ampliar o diálogo multilateral e potencializar os mecanismos de cooperação, para promover ações mais efetivas, subnacionais e localizadas, sobre a agenda. Em tempo de recrudescimento de posições marcadas pela afirmação do discurso único, é urgente afirmar os múltiplos diálogos e ampliar as vozes na defesa de uma agenda de população e desenvolvimento vinculada aos direitos humanos. 


\section{Referências}

ABEP - Associação Brasileira de Estudos Populacionais; UNFPA - Fundo de População das Nações Unidas. Brasil, 15 anos após a Conferência do Cairo. Campinas: Abep, UNFPA, 2009. Disponível em: 〈http://www.abep.org.br/publicacoes/index.php/livros/issue/view/13/showToc〉. Acesso em: 20 abr. 2015.

ABEP - Associação Brasileira de Estudos Populacionais; UNFPA - Fundo de População das Nações Unidas. Dez anos do Cairo: tendências de fecundidade e direitos reprodutivos no Brasil. Campinas: Abep, UNFPA, 2004. Disponivel em: 〈http://www.abep.org.br/publicacoes/index. php/livros/issue/view/14/showToc>. Acesso em: 20 abr. 2015.

ALVES, J. A. L. Relações internacionais e temas sociais: a década das conferências. Brasília: Instituto Brasileiro de Relações Internacionais, 2001.

ALVES, J. E. D. População, desenvolvimento e sustentabilidade: perspectivas para a CIPD pós-2014. Revista Brasileira de Estudos de População, São Paulo, v. 31, n. 1, p. 219-230, 2014. Disponível em: 〈http://www.scielo.br/scielo.php?script=sci_arttext\&pid=S0102-30982014000100013\&ln $\mathrm{g}=$ en\&nrm=iso>. Acesso em: 28 out. 2019.

ARILHA, M.; LAGO, T. (org.). Cairo+20 e políticas públicas no Brasil: consolidando e ampliando direitos. São Paulo: Oficina Editorial, 2014.

BERQUÓ, E. As posições da OMS nas conferências de população da ONU nos últimos 50 anos. In: WONG, L. R. et al. Cairo+20: perspectivas de la agenda de población y desarrollo sostenible después de 2014. Rio de Janeiro: Alap, 2014. p. 17-22.

BERQUÓ, E. Refletindo sobre as questões populacionais neste final de século. Novos Estudos, São Paulo, n. 55, p. 71-81, 1999.

CAMARANO, A. Perspectivas para o Cairo+20: como avançar na discussão sobre população e desenvolvimento. Revista Brasileira de Estudos de População, São Paulo, v. 30, n. 2, jul./dez. 2013.

CAMARANO, A. (org.). Novo regime demográfico: uma nova relação entre população e desenvolvimento? Rio de Janeiro: Ipea, 2014.

MARTINS, R. Participação social, população e desenvolvimento no Brasil (1994-2014): a emergência da sociedade civil e novas leituras sobre o monitoramento de políticas públicas para a análise da política externa. Dissertação (Mestrado) - Universidade Federal do Rio de Janeiro (UFRJ), Rio de Janeiro, 2017.

UNFPA - Fundo de População das Nações Unidas. Plano da Conferência Internacional sobre População e Desenvolvimento. Brasília, 2004.

\section{Sobre o autor}

Richarlls Martins é doutorando em Saúde Coletiva no Programa de Pós-Graduação em Saúde da Criança e da Mulher (PPGSCM), Fundação Oswaldo Cruz (Fiocruz) e mestre em Políticas Públicas em Direitos Humanos pela Universidade Federal do Rio de Janeiro (UFRJ). Professor da UFRJ e coordenador geral da Rede Brasileira de População e Desenvolvimento (REBRAPD).

\section{Endereço para correspondência}

Rua São Salvador, 99/801

22231-130 - Rio de Janeiro-RJ, Brasil 